\title{
Características agronômicas e bromatológicas de híbridos de milho para produção de silagem ${ }^{1}$
}

\section{Solidete de Fátima Paziani 2,3 , Aildson Pereira Duarte ${ }^{2}$, Luiz Gustavo Nussio ${ }^{4}$, Paulo Boller Gallo², Carla Maris Machado Bittar ${ }^{4}$, Maity Zopollatto ${ }^{4}$, Paulo César Reco ${ }^{2}$}

\footnotetext{
${ }^{1}$ Programa Milho, IAC/APTA/ESALQ.

2 Secretaria de Agricultura e Abastecimento do Estado de São Paulo, Agência Paulista de Tecnologia dos Agronegócios/APTA.

3 Pólo APTA, Caixa Postal 24, Pindorama/SP, CEP: 15830-000.

${ }^{4}$ Escola Superior de Agricultura Luiz de Queiroz, USP/ESALQ, Departamento de Zootecnia, Piracicaba/SP.
}

\begin{abstract}
RESUMO - Objetivou-se estabelecer correlações entre características quantitativas e qualitativas e avaliar a influência dessas características sobre a produção e a qualidade do milho para silagem. Utilizaram-se dados do Programa de Avaliação de Cultivares de Milho para Silagem IAC/APTA/ESALQ para cálculo das correlações de Pearson entre as variáveis. A produção de matéria seca (MS) digestível foi afetada tanto pelas produções de massa e de grãos quanto pelas digestibilidades da planta e do colmo. A produção de matéria seca digestível apresentou os maiores coeficientes de correlação com a produção de MS $(0,85)$; com as produções de grãos na ensilagem $(0,60)$ e na maturidade $(0,68)$; com produção de matéria verde $(0,47)$ e com o índice de espigas $(0,48)$. Os coeficientes de correlação entre a produção de matéria seca digestível e a digestibilidade da planta inteira $(0,44)$ e da fração colmo $(0,38)$ foram inferiores aos obtidos para a produção de matéria seca. A digestibilidade da planta dependeu principalmente da digestibilidade do colmo $(0,60)$ e dos parâmetros relacionados aos grãos. $\mathrm{Na}$ ausência de informações específicas sobre os cultivares de milho para silagem, pode-se optar por aqueles de maior produção de grãos à maturidade, em razão da elevada correlação dessa característica com produção de matéria seca e com produção de matéria seca digestível.
\end{abstract}

Palavras-chave: correlação, digestibilidade, grãos, matéria seca, proteína, Zea mays

\section{Agronomic and nutritional characteristics of the corn hybrids for silage production}

\begin{abstract}
The objective of this work was to establish correlations between quantitative and qualitative variables and to evaluate their influence on the corn quality for ensilage production. Data from the Corn Hybrids for Silage Evaluation Program were used (IAC/APTA/ESALQ). Pearson correlations between the variables were calculated. The digestible dry matter (DM) production was affected not only by forage and grain productions, but also by the whole plant and stem digestibility. The digestible dry matter production presented the highest correlation coefficients with the total dry matter production (0.85) and with the grain production at ensiling (0.60) and maturity (0.68), production of fresh forage (0.47) and with the plant ears index (0.48). The correlation coefficients between the digestible DM production and the whole plant digestibility (0.44) and the stem fraction (0.38) were lower than those observed for the DM production. The whole plant digestibility depended mainly on the stem digestibility $(0.60)$ and on parameters related to the grains. It may be concluded that when specific information on corn hybrids is not available, those with higher production of grains at maturity are selected due to their elevated correlation with DM production and digestible DM.
\end{abstract}

Key Words: correlation, digestibility, dry matter, grains, protein, Zea mays

\section{Introdução}

As características mais desejáveis em uma cultura para ensilagem são a elevada produção de matéria seca, as altas concentrações de proteína bruta e energia (alta digestibilidade) e o elevado teor de matéria seca (baixa concentração de fibra) na colheita para favorecer a fermen- tação. O baixo teor de PB, fator nutricional limitante ao desempenho animal, é contornado com o fornecimento de uma fonte de nitrogênio (Lauers, 2001).

O milho é a cultura padrão para ensilagem, pela tradição no cultivo, pela elevada produtividade e pelo bom valor nutritivo. Além disso, a ênfase no uso de híbridos mais produtivos e adaptados às condições locais é responsável 
pelos ganhos em produtividade de massa dessa cultura. Apesar da busca por cultivares com elevada quantidade de grãos na massa (Cox et al., 1994; Lauers, 2001) para melhorar a digestibilidade, de modo geral, sempre houve pouco interesse na melhoria da qualidade da forragem (Lauers et al., 2001; Ferrari Jr. et al., 2005; Jaremtchuk et al., 2005). Entretanto, com a crescente melhora no padrão genético dos animais e com a intensificação da produção pecuária, aumenta-se também a exigência na qualidade da silagem.

Além dos parâmetros agronômicos, as proporções das frações da planta também influenciam a qualidade final da silagem (Almeida Filho et al., 1999; Rosa et al., 2004; Ferrari Jr. et al., 2005; Mendes et al., 2006). Ainda não existem estudos amplos e não foram estabelecidas correlações entre a produtividade de grãos após a maturidade fisiológica e a produção de massa para silagem. O estudo das relações entre as diversas características da planta permite direcionar a seleção, favorecendo as características de produtividade e qualidade mais correlacionadas (Gomes et al., 2004).

Há no mercado grande número de cultivares de milho com variados índices de produtividade e qualidade, porém, é necessário considerar a influência dos fatores ambientais e das práticas de manejo (Almeida Filho et al., 1999), que, juntamente com o genótipo, definem o padrão de desenvolvimento da cultura. Assim, o desenvolvimento dos mesmos cultivares pode variar entre ambientes, o que requer avaliação sobre essa variabilidade regional (clima, solo e outros).

Este trabalho foi realizado com os objetivos de estabelecer correlações entre características quantitativas e qualitativas e avaliar a influência dessas características sobre a produção e a qualidade do milho para silagem em experimentos de avaliação de cultivares no estado de São Paulo.

\section{Material e Métodos}

Utilizou-se o banco de dados do Programa de Avaliação de Cultivares de Milho para Silagem, realizado em parceria com o Instituto Agronômico de Campinas (IAC), Agência Paulista de Tecnologia dos Agronegócios (APTA), Escola Superior de Agricultura Luiz de Queiroz (ESALQ), obtidos nas safras de 1998/1999 a 2004/2005. Empregaram-se, dependendo da característica em estudo, dados de 4 a 7 anos, obtidos com 15 a 24 cultivares de ciclo precoce e médio e 3 a 4 locais por ano, totalizando 13 a 25 ambientes e 333 a 480 informações. Os ensaios foram instalados em quatro localidades do estado de São Paulo, inicialmente nos municípios de Tarumã, Mococa, Piracicaba e Votuporanga. Posteriormente, o ensaio de Tarumã foi deslocado para Cândido Mota e depois para Assis, enquanto o ensaio de Piracicaba passou a ser realizado em Pindamonhangaba (Tabela 1). Ao longo deste período, os ensaios foram feitos em parcelas com 6 linhas de $5 \mathrm{~m} \mathrm{e}$ espaçamento entre linhas de 80 a $90 \mathrm{~cm}$. A época de semeadura variou de outubro a dezembro e a época de colheita, de janeiro a abril. A população inicial após desbaste foi de 55 a 57,5 mil plantas/ha e a correção do solo foi feita com base nos resultados da análise de solo e nas recomendações do Boletim 100 do IAC.

O delineamento experimental foi o de blocos ao acaso com quatro repetições, utilizando-se as linhas centrais para as avaliações (duas linhas colhidas no ponto de ensilagem e duas linhas para grãos após a maturidade fisiológica). A colheita para ensilagem foi realizada quando o teor de matéria seca (MS) na planta inteira atingiu por volta de $34 \%$, determinando-se o teor de MS nas plantas das bordaduras, em forno de microondas, conforme método descrito por Valentini et al. (1998).

Em duas linhas centrais, contaram-se o número total de plantas e o número de plantas quebradas e de plantas acamadas. Essas duas linhas foram cortadas e pesadas separadamente para determinação da massa verde de cada uma. Amostraram-se cinco plantas por linha, dez plantas por parcela, as quais foram avaliadas quanto às alturas das plantas e espigas e quanto ao número de folhas verdes e secas. Em seguida, as plantas foram fracionadas em colmo+pendão, folhas e espigas, que foram pesados separadamente. Posteriormente, os sabugos + grãos foram separados da palha e, depois de secos em estufa, os grãos foram pesados. Os colmos foram triturados e as folhas picadas retirando-se uma amostra para secagem e determinação do teor da $\mathrm{MS}\left(60^{\circ} \mathrm{C}\right)$. Outras dez plantas íntegras por parcela, cinco por linha, foram trituradas retirando-se uma amostra para determinação do teor de matéria seca.

As amostras de planta inteira e colmo foram secas a $60^{\circ} \mathrm{C}$ (Silva, 1990) em estufa de ventilação forçada e trituradas em moinho Wiley com peneira de malha de $1 \mathrm{~mm}$. Os espectros das amostras foram obtidos em intervalos de $2 \mathrm{~nm}$, em amplitude de 1.100 a $2.498 \mathrm{~nm}$, utilizando-se o aparelho NIRSystem 5000 (Foss NIR Systems Inc., Silver Spring, MD, USA), e os dados foram armazenados como log 1/R $(\mathrm{R}$ = refletância). O teor de proteína bruta e as digestibilidades do colmo e da planta inteira foram estimados a partir de curvas de calibração já existentes e com valores adequados de erro-padrão da calibração (SEC) e validação cruzada (SECV), e altos valores de coeficiente de determinação da calibração (R2) e validação cruzada (1-VR), conforme descrito por Mello et al. (2006). 


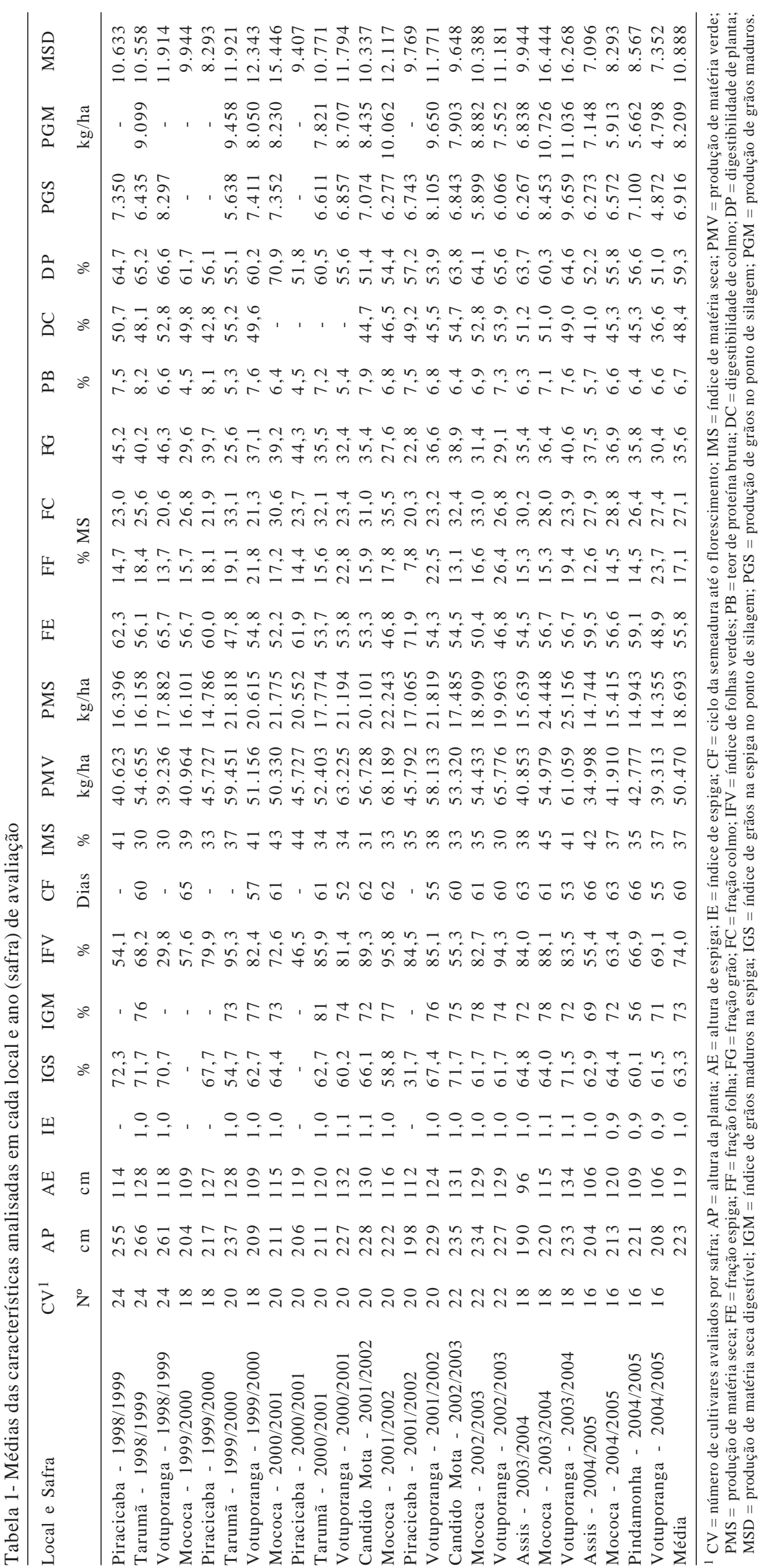


Com base no peso das plantas de cada linha e no seu respectivo teor de matéria seca, calcularam-se as produtividades de matéria verde, matéria seca, matéria seca digestível e grãos no momento da ensilagem. Após a maturidade dos grãos, procedeu-se à colheita de duas linhas úteis centrais na parcela para avaliação da produtividade de grãos corrigida para 13,0\% de umidade e determinação do índice de grãos nas espigas. $\mathrm{O}$ ciclo da semeadura até o florescimento masculino foi avaliado quando $50 \%$ das plantas apresentavam-se com o pendão aberto.

Os dados dos cultivares em cada ano e local foram analisados pelo procedimento ANOVA e $\mathrm{P}<0,05$ (SAS, 1990). Calcularam-se correlações de Pearson (PROCORR) de 20 variáveis, visando conhecer a intensidade com que as variáveis influenciam e são influenciadas por outras. Os fatores que alteraram as variáveis foram o ambiente, representado por ano e local, e os cultivares incluídos no modelo.

\section{Resultados e Discussão}

A produção de massa verdeéum dos primeiros parâmetros a avaliar quando se busca informação sobre determinado cultivar, uma preocupação anterior aos parâmetros de qualidade da silagem; além de ser um parâmetro para o dimensionamento de silos (Ferrari Jr. et al., 2005), também contribui para a diluição dos custos de implantação da cultura por elevar a produtividade. As produtividades médias de massa verde (50,47 t/ha) e matéria seca (18,69 t/ha) obtidas neste trabalho (Tabela 1 ) foram superiores às amplitudes de 31,37 a 44,96 t MV/ha e de 11,46 a 17,26 t MS/ha observadas na literatura (Almeida Filho et al., 1999; Ferrari Jr. et al., 2005; Mendes et al., 2006) e podem ser consideradas ótimas em comparação às médias obtidas na prática, apesar dos espaçamentos maiores ( $90 \mathrm{a} 100 \mathrm{~cm}$ ) entre linhas normalmente utilizados, o que pode ter contribuído para a menor massa de forragem descrita na literatura.

Entretanto, além da produção total de massa, também deve ser considerada a qualidade da silagem, que é influenciada pela proporção dos componentes da planta. As proporções de espigas (55,8\% da MS) e colmos (27,1\% da MS) (Tabela 1) obtidas neste trabalho foram superiores às reportadas na literatura (Almeida Filho et al., 1999; Rosa et al., 2004; Jaremtchuk et al., 2005), mas, conforme descrito por Jaremtchuck et al. (2005), o uso de cultivares de porte médiobaixo pode refletir na menor participação de colmos (18 a 25\%) e, de acordo com Rosa et al. (2004), além da restrição hídrica prejudicar o desenvolvimento das espigas.

A participação de grãos na MS (35,6\%) observada foi idêntica à observada por Ferrari Jr. et al. (2005) e superior à de $29,5 \%$ relatada por Rosa et al. (2005), que observaram condições de deficiência hídrica. O teor de PB de 6,7\% foi inferior ao observado por alguns autores (Almeida Filho et al., 1999; Lauers et al., 2001; Ferrari Jr. et al., 2005; Mendes et al., 2006) e a digestibilidade de planta inteira (59,3\%) esteve entre os 54,92 e 61,72\% observados por Almeida Filho et al. (1999) e Ferrari Jr. et al. (2005).

O rendimento de grãos na espiga foi de $63,3 \%$ no ponto de ensilagem e de $73 \%$ na maturidade, o que comprova o potencial para deposição de MS entre o ponto de ensilagem e a maturidade (Tabela 1). Outros dados contrastantes foram os valores de digestibilidade de colmo $(48,4 \%)$ e da planta inteira (59,3\%), uma vez que a fração colmo reduz a digestibilidade da planta. A importância em conhecer os valores de produtividade, participação das frações da planta e qualidade dessas frações, além de identificar os cultivares mais adaptados pela expressão de seu potencial produtivo, também permite estabelecer correlações entre estas variáveis e a produtividade e qualidade do milho para silagem.

A produção de matéria seca digestível apresentou maior correlação, seja positiva ou negativa, com todos os parâmetros quantitativos e qualitativos, à exceção da fração grão na planta (Tabela 2). Os maiores coeficientes de correlação foram observados com a produção de MS total $(0,85)$, os parâmetros agronômicos de produção de grãos na ensilagem e maturidade ( 0,60 e 0,68 , respectivamente), a produção de matéria verde $(0,47)$ e com o índice de espigas por planta $(0,48)$. Os parâmetros de produção de grãos na ensilagem e na maturidade, produção de massa verde e índice de espiga apresentaram os maiores coeficientes de correlação com a própria produção de MS.

Os coeficientes de correlação entre a produção de matéria seca digestível e a digestibilidade da planta inteira $(0,44)$ e a fração colmo $(0,38)$ foram inferiores ao observado para a produção de matéria seca. A digestibilidade da planta dependeu principalmente da digestibilidade do colmo $(0,60)$ e dos parâmetros relacionados aos grãos $(r \leq 0,36)$.

As produções de matéria verde e seca não se correlacionaram $(\mathrm{P}>0,05)$ com a digestibilidade da planta inteira, embora Roth et al. (1970) tenham observado correlações negativas entre a produção de matéria seca por planta e a digestibilidade da matéria seca. No entanto, neste trabalho, as produções de massa verde e matéria seca apresentaram correlações positivas com a digestibilidade do colmo (os coeficientes de correlação foram 0,25 e 0,28, respectivamente). Logo, as maiores produções de matéria seca digestível nas condições estudadas foram ocasionadas principalmente pelos ambientes e cultivares de milho 


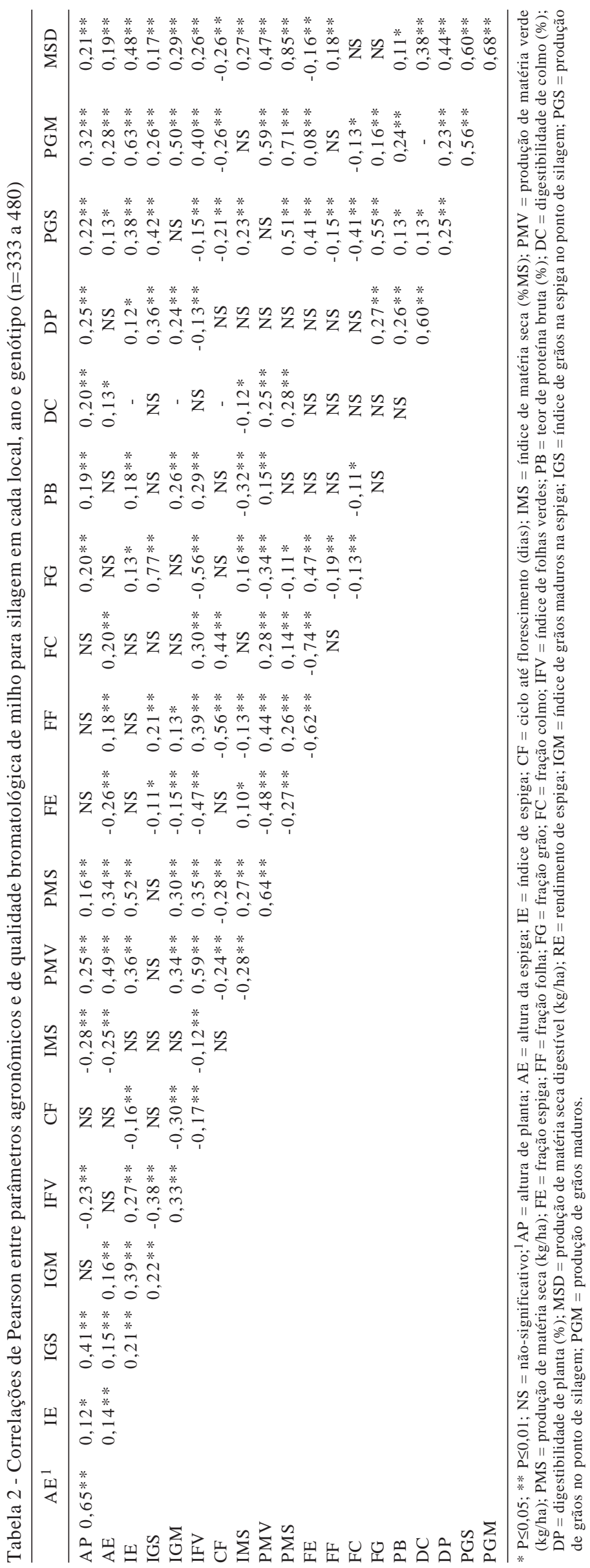

propícios à produção de massa da planta inteira e à produção de grãos.

O porte da planta, representado pelas alturas de plantas e de espigas, apresentou maiores coeficientes de correlação com as produções de massa verde, de massa seca, de grãos, de matéria seca digestível; com o índice de grãos na espiga no momento da ensilagem, e com a digestibilidades da planta inteiro e do colmo $(r=0,13$ a 0,49$)$, exceto entre a altura de espiga e a digestibilidade da planta inteira, cujos coeficientes de correlação não foram significativos.

Houve correlação positiva entre altura de planta e maior produção de massa ver de e seca $(0,25$ e 0,16$)$ e produção de grãos no ponto de ensilagem e na maturidade $(0,22$ e 0,32$)$ e entre altura e melhor digestibilidade do colmo $(0,20)$ e da planta inteira $(0,25)$ em plantas de maior porte. Albrecht \& Dudley (1987) também observaram correlação positiva entre altura de planta e produção de grãos na maioria das populações estudadas $(0,11$ a 0,59$)$. Os valores observados neste trabalho foram inferiores aos obtidos por Mendes et al. (2006), que encontraram correlação positiva entre altura da planta e de espiga e a produção de massa verde e seca e elevadas correlações entre altura de planta e produção de grãos $(0,57)$, altura de espiga $(0,83)$, produção de massa verde $(0,63)$ e de massa seca $(0,66)$. Neste trabalho, a altura das plantas não teve correlações significativas com as frações espiga, colmo e folhas, ao contrário do observado por Schmid et al. (1976), que verificaram maior participação de folhas $(0,20)$ e colmos $(0,47)$ e menor de espigas $(-0,35)$ com o aumento da altura de plantas. Além disso, neste trabalho, as plantas mais altas foram colhidas com menor índice de matéria seca $(\mathrm{r}=-0,28)$.

O estudo das produções de massa verde e seca indica que os maiores valores ocorreram com a elevação nas proporções de folhas $(0,44$ e 0,26$)$ e colmos $(0,28$ e 0,14$)$ e nas menores proporções de espigas $(-0,48$ e $-0,27)$ e grãos $(-0,34$ e $-0,11)$. Entre todas as frações, folha e colmo se correlacionaram negativamente com espiga $(-0,62$ e -0,74) e grãos (-0,19 e -0,43), o que evidencia o efeito de diluição destas frações com o aumento da porção forrageira da planta, fato também observado por Ferrari Jr. et al. (2005) e Roth et al. (1970), ou seja, coeficiente de correlação negativo entre produção de massa verde e produção de MS com as proporções de grãos e de espigas na massa $(r=-0,31)$.

De modo geral, a precocidade no florescimento favoreceu a produção de milho para silagem e híbridos com ciclos mais precoces apresentaram maiores valores de produção de massa verde, massa seca, produção de grãos na maturidade e na ensilagem, índice de grãos na espiga na ensilagem e na maturidade e matéria seca digestível ( $r=-0,19$ a -0,30). A precocidade resultou ainda em maior proporção de folhas 
$(r=-0,56)$ e menor proporção de colmo nas plantas $(r=0,44)$, mas reduziu o índice de folhas verdes $(-0,17)$.

O índice de folhas verdes correlacionou-se positivamente com as frações colmo e folhas ( 0,30 e 0,39$)$, produção de massa verde $(0,59)$, produção de massa seca $(0,35)$, com a produção de grãos na maturidade fisiológica $(0,40)$, produção de MS digestível $(0,26)$ e com o teor de proteína bruta $(0,29)$, indicando sua contribuição na elevação da quantidade e qualidade de massa para ensilagem. No entanto, o índice de folhas verdes correlacionou-se negativamente com a fração espigas $(-0,47)$, a fração grãos $(-0,56)$, o índice de grãos na espiga no ponto de ensilagem $(-0,38)$, a produção de grãos no momento da ensilagem $(-0,15)$ e, conseqüentemente, com a digestibilidade da planta $(-0,13)$. O índice de folhas verdes e a fração folhas, por estarem associados $(0,39)$, apresentaram correlações similares com a maioria das outras variáveis. Embora os maiores valores de folhas verdes possam ser explicados parcialmente pelo corte das plantas com menor índice de matéria seca $(\mathrm{r}=-0,12)$, a menor proporção de espigas e grãos nas plantas com mais folhas verdes não significa necessariamente que a colheita da maior parte dos híbridos tenha sido antecipada em relação ao desenvolvimento dos grãos.

Apesar de o aumento na produção de massa verde e matéria seca reduzir a participação das espigas e dos grãos e elevar as frações colmo e folhas, não houve redução na produção de grãos no momento da ensilagem e após maturidade fisiológica dos grãos nem na produção de matéria seca digestível. A produção de matéria seca digestível depende de outros fatores como digestibilidade de planta inteira e de colmo e não somente do teor de grãos na massa.

Cox et al. (1984) observaram correlação positiva entre produção de MS e índice de grãos maduros na espiga (0,11 a 0,21 ) e demonstraram que o rendimento de grãos é um dos fatores que mais influenciam a produção de MS e a correlação negativa entre produção de MS e frações fibrosas (FDN, FDA e lignina), o que elevaria a digestibilidade da matéria seca. Nesse contexto, Schmid et al. (1976) observaram que a elevação na participação das espigas reduz o teor de FDA $(-0,87)$ e eleva a MS digestível $(0,67)$, reduzindo a participação de colmo $(-0,97)$ e folhas $(-0,97)$ e elevando a ingestão de MS $(0,73)$ e o ganho de peso diário $(0,68)$.

As frações espiga e grãos apresentaram valores de correlação positivos com a produção de grãos no momento da ensilagem $(0,41$ e 0,55$)$, o que confirma dados obtidos por Fairey (1980), que encontraram correlação positiva entre a porcentagem de grãos na matéria seca e a produção de grãos $(r=0,35$ a 0,95$)$. As correlações entre as frações colmo, folhas, grãos e espigas no momento da ensilagem e a produtividade de grãos na maturidade fisiológica não foram significativas ou apresentaram baixos coeficientes de correlação $(r<0,16)$.

Uma vez que parte dos componentes fotoassimilados é translocada para a espiga depois do florescimento das plantas e o corte para ensilagem é feito antes da maturidade fisiológica dos grãos, observaram-se maiores valores das frações folhas e colmos quando os cultivares e/ou as condições de desenvolvimento das plantas proporcionam maior acúmulo de matéria seca. Por isso, nas colheitas mais tardias, a quantidade de grãos na planta foi maior; o índice de matéria seca correlacionou-se positivamente com a produção de grãos no momento da ensilagem $(0,23)$ e com as frações espiga $(0,10)$ e grãos $(0,16)$.

O teor de proteína correlacionou-se positivamente com o índice de folhas verdes $(0,29)$, com a proporção de grãos na espiga na maturidade $(0,26)$ e a produção de grãos na ensilagem e maturidade (0,13 e 0,24). A importância das folhas verdes na predição do teor de proteína é reforçada pela correlação negativa entre a proteína e o índice de matéria seca $(-0,32)$; plantas com menores índices de matéria seca indicam maior proporção de folhas verdes $(\mathrm{r}=-0,12)$. A proteína e a digestibilidade da planta se correlacionaram positivamente $(0,26)$, provavelmente porque ambas foram influenciadas favoravelmente pelos parâmetros relacionados aos grãos. A correlação entre teor de proteína e produção de matéria verde foi positiva, mas muita baixa $(0,15)$, ao contrário do observado por Mendes et al. (2006), que constataram decréscimo do teor de proteína bruta com o aumento das produções de massa verde e matéria seca ( $r=-0,51$ para ambas).

A produção de grãos após a maturidade correlacionou-se positivamente com a produção de MS $(0,71)$ e de matéria verde $(0,59)$; com a produção de grãos no ponto de silagem $(0,56)$; e com a produção MS digestível $(0,68)$. Este fato também foi observado por Mendes et al. (2006), que citam elevados índices de correlação entre produção de grãos na maturidade e produção de MS $(0,75)$ e produção de massa verde $(0,81)$. Logo, quando não houver informações específicas sobre os cultivares de milho para silagem, pode-se empregar para este fim os genótipos mais adaptados regionalmente para a produção de grãos. Complementarmente, deve-se observar a produção de massa verde e seca, que podem ser inferidas indiretamente pela altura da planta e espiga.

Atualmente, no Brasil, não existe cultivar de milho recomendado somente para produção de silagem. Além disso, uma lavoura implantada para produção de silagem pode ser redirecionada para a colheita de grãos, em 
virtude das oscilações dos preços dos produtos animais e/ou do próprio grão. Embora os resultados encontrados neste estudo demonstrem que é possível utilizar o mesmo cultivar para diferentes fins, deve-se procurar escolher aqueles com maior produção de matéria seca digestível.

\section{Conclusões}

As produções de matéria seca e matéria verde e a produção de grãos, tanto no ponto de ensilagem como na maturidade, são os fatores que mais afetam a produção de massa seca digestível. Portanto, em situações em que não há informações específicas sobre os cultivares de milho para silagem, pode-se optar pelos cultivares com maiores produções de grãos à maturidade pelo elevado grau de correlação entre essas características.

\section{Agradecimentos}

Aos participantes Erasmo A. Oliveira e Santos, José Carlos Pugliezi, Sérgio José Coradello, Wilson L. Strada, Fabiana A. Cruz e Carlos César Alves, que colaboraram durante a execução deste trabalho.

\section{Literatura Citada}

ALBRECHT, B.; DUDLEY, J.W. Divergent selection for stalk quality and grain yield in an adapted $\mathrm{x}$ exotic maize population cross. Crop Science, v.27, n.1, p.487-494, 1987.

ALMEIDA FILHO, S.L.; FONSECA, D.M.; GARCIA, R. et al. Características agronômicas de cultivares de milho (Zea mays L.) e qualidade dos componentes da silagem. Revista Brasileira de Zootecnia, v.28, n.1, p.7-13, 1999.

COX, W.J.; CHERNEY, J.H.; CHERNEY, D.J.R. et al. Forage quality and harvest index of corn hybrids under different growing conditions. Agronomy Journal, v.86, n.2, p.277-282, 1994.

FAIREY, N.A. Hybrid maturity and the relative importance of grain and stover for the assessment of the forage potential of maize genotypes grown in marginal and non-marginal environments. Canadian Journal of Plant Science, v.60, n.2, p.539-545, 1980.

FERRARI JR., E.; POSSENTI, R.A.; LIMA, M.L. et al. Características, composição química e qualidade de silagens de oito cultivares de milho. Boletim de Indústria Animal, v.62, n.1, p.19-27, 2005.

GOMES, M.S.; Von PINHO, R.G.; RAMALHO, M.A.P. et al. Variabilidade genética em linhagens de milho nas características relacionadas com a produtividade de silagem. Pesquisa Agropecuária Brasileira, v.39, n.9, p.879-885, 2004.

JAREMTCHUK, A.R.; JAREMTCHUK, C.C.; BAGIOLI, B. et al. Características agronômicas e bromatológicas de vinte genótipos de milho (Zea mays L.) para silagem na região leste paranaense. Acta Scientiarum, v.27, n.2, p.181-188, 2005.

LAUERS, J.G.; COORS, J.G.; FLANNERY, P.J. Forage yield and quality of corn cultivars developed in different eras. Crop Science, v.41, p.1449-1455, 2001.

MELLO, R.; BITTAR, C.M.M.; QUEIROZ, A.C. et al. Validação de modelos de calibração multivariada para predição da qualidade de silagens de milho pela espectroscopia no infravermelho próximo. In: REUNIÃO ANUAL DA SOCIEDADE BRASILEIRA DE ZOOTECNiA, 43., 2006, João Pessoa. Anais... João Pessoa: Sociedade Brasileira de Zootecnia, 2006. (CD-ROM).

MENDES, M.C.; Von PINHO, R.G.; LIMA, T.G. et al. Associação entre características e desempenho de híbridos de milho para produção de forragem. In: CONGRESSO NACIONAL DE MILHO E SORGO, 26., 2006, Belo Horizonte. Anais... Belo Horizonte: ABMS, 2006. p.203.

ROSA, J.R.P.; SILVA, J.H.S.; RESTLE, J. et al. Avaliação do comportamento agronômico da planta e valor nutritivo da silagem de diferentes híbridos de milho (Zea mays, L.). Revista Brasileira de Zootecnia, v.33, n.2, p.302-312, 2004.

ROTH, L.S.; MARTEN, G.C.; COMPTON, W.A. et al. Genetic variation of quality traits in maize (Zea mays L.) forage. Crop Science, v.10, n.1, p.365-367, 1970.

STATISTICAL ANALYSIS SYSTEM - SAS. User's guide: statistics. 4.ed. Cary: SAS Institute, 1990. 956p.

SCHMID, A.R.; GOODRICH, R.D.; JORDAN, R.M. et al. Relationships among agronomic characteristics of corn and sorghum cultivars and silage quality. Agronomy Journal, v.68, n.1, p.403-406, 1976.

SILVA, D.J. Análise de alimentos: métodos químicos e biológicos. Viçosa, MG: Universidade Federal de Viçosa, 1990. 165p.

VALENTINI, S.R.; CASTRO, M.F.P.M.; ALMEIDA, F.H. Determinação do teor de umidade de milho utilizando aparelho de microondas. Ciência e Tecnologia de Alimentos, v.18, n.2, p.237-240, 1998. 